\title{
Editorial
}

\section{Management Story}

With some envy the people who work closely with Phenomenology + Pedagogy note how the powerful machineries of major journals are able to send flyers, advertisements, letters, and reminders which prod, plead, persuade, coax, and cajole in an effort to make themselves more popular. Other journals need to worry less because they are the agencies of professional associations. Support and circulation is assured through membership dues or organizational resources.

What does editorial management mean to us at Phenomenology + Pedagogy? We are neither big nor supported by a wealthy association. This journal grew out of a desire to provide support and stimulation to alternative research efforts and thoughtful practices in education. We rely on the interest and the enthusiasm of collaborators and readers to legitimate or justify the project of phenomenology and pedagogy. Robert Frost is purported to have said,

Man likes to bring two things together into one ... He lives by making associations, and he is doing well by himself and in himself when he thinks of something in connection with something else that no one ever put with it before.

Phenomenology + Pedagogy thrives on the diversity of connections it is continuously having to make; the connections writers make with our readers, those our Editor makes by way of introducing the rich élan brought together in each new publication, and finally, not to be overshadowed by the rest, the connections we make by way of subscriptions that expand the readership of Phenomenology + Pedagogy. The latter is crucial to us at the offices of Phenomenology + Pedagogy. We need you, the reader of Phenomenology + Pedagogy, to feel a certain eros: An eros that moves you intellectually and actively to help the journal establish strong connections. You can help the project of the journal by continuing to subscribe to the journal. Should you already be a subscribing member, take time to introduce Phenomenology + Pedagogy to someone unfamiliar with it.

Journal members can give Phenomenology + Pedagogy a tremendous boost if each member can help us gain a new subscription. Does your library carry Phenomenology + Pedagogy? Are there any suggestions that you can make to help the journal grow? Make the connection! 